\title{
Cutting Force in Stone Machining by Diamond Disk
}

\author{
S. Turchetta \\ Dipartimento di Ingegneria Industriale, Università Degli Studi di Cassino, Via G. di Biasio 43, 03043 Cassino, Italy \\ Correspondence should be addressed to S. Turchetta, turchetta@unicas.it
}

Received 7 June 2010; Revised 1 September 2010; Accepted 6 October 2010

Academic Editor: João Paulo Davim

Copyright $\odot 2010$ S. Turchetta. This is an open access article distributed under the Creative Commons Attribution License, which permits unrestricted use, distribution, and reproduction in any medium, provided the original work is properly cited.

\begin{abstract}
Stone machining by diamond disk is a widespread process to manufacture standard products, such as tiles, slabs, and kerbs. Cutting force and energy may be used to monitor stone machining. Empirical models are required to guide the selection of cutting conditions. In this paper, the effects of cutting conditions on cutting force and cutting energy are related to the shape of the idealized chip thickness. The empirical models developed in this paper can be used to predict the variation of the cutting energy. Therefore these models can be used to guide the selection of cutting conditions. The chip generation and removal process has been quantified with the intention of assisting both the toolmaker and the stonemason in optimising the tool composition and cutting process parameters, respectively.
\end{abstract}

\section{Introduction}

Cutting force and energy are important parameters to better understand the machining process, since they are directly related to tool wear, cutting temperatures, and surface integrity. In stone machining abrasive grits pass on machined surface by removing stone mineral constituents. To understand the prevailing mechanism of abrasive-workpiece interactions during stone machining is a necessary step in order to efficiently use the cutting process. The understanding of the cutting phenomena leads to models that voice the relationship between cutting behaviour and control parameters. In order to achieve better control of a cutting process, a model is required to demonstrate the relationship between cutting and control parameters.

Very few researches exist in the literature on stone cutting. Jerro et al. [1] showed a mathematical approach to define and derive theoretical chipping geometries. From the knowledge of the theoretical chipping geometries, chip area and mean chip thickness relations were obtained. The relationship between tangential cutting force and obtained chip thickness is empirically investigated. Brach et al. [2] studied the problem to convert dynamometer readings of specific cutting energy into power consumed. Asche et al. [3] showed the empirical results of the influence of process parameters on tool wear. Tönshoff and Warnecke [4] developed a model on stone cutting by disc-like diamond tools that is widely used even if it is not completely tested. The model shows the mechanical interaction of tool and workpiece as caused by the elastic and plastic workpiece deformation of the cutting grits, the friction between stone and diamonds, stone and matrix, and swarf and matrix. Konstanty [5] presented a theoretical model of natural stone sawing by means of diamond impregnated tools for both circular and frame sawing. These models seem not to have been tested by means of experiments. Pai et al. [6] collected and observed chip samples under a scanning microscope and related them to the specific grinding energy. Wang and Clausen [7] simulated the cutting process of diamond grit by single-point cutting tools and demonstrated that the tendency of cutting forces and characters of grooves are similar. Di Ilio and Togna [8] showed an analytical model to foresee the maximum wear rates of grains and matrix which provide evidence of the wear mechanism. It is based on the assumption that tool wear rate depends on two basic factors: the former being only a matrix characteristic and the latter only a grain characteristic, both to be determined experimentally. Ersoy et al. [9] established a relationship among the cutting specific energy, the wear of the diamond saw, and the rock properties for different rock types. These investigations do not try to give an organic comprehension of phenomena that happen at the tool-workpiece interface during stone cutting. 
The literature offers many works on grinding of ductile or brittle materials. Malkin and Hwang [10] proposed an interesting model of the relationship between the grinding power and the rate of plowed surface area generated by abrasive cutting grits that interact with the workpiece in ceramics. He deepened the model by taking into account the influence of the rounding at the tip of the triangularshaped grit on the specific grinding energy [11]. The work on metal grinding shows many approaches to model grinding force [12]. They are based on empirical [13] or physical considerations [14].

The present work models the widespread process of stone machining by electroplated diamond disk. The diamond grits on the tool surface remove material through the cracking of the stone volume. The cut is mainly influenced by the physical-mechanical stone material properties, like grit size and strength: different minerals have different effects on the cutting mechanism, on the binder abrasion, and on the diamond wear. Other factors influencing this process are the forces between diamonds and material, the stress distribution in the rock, the temperatures in the toolworkpiece interface.

This work aims to investigate the relationship among the cutting force and energy and the relevant cutting parameters, such as the depth of cut and the feed rate. In particular, the machining conditions that are most interesting from an industrial point of view have been investigated. The cutting force and energy have been modelled as a function of equivalent chip thickness and material removal rate (MRR) by simple and general power function. The obtained models have been tested for different values of process parameters.

In the following the models developed for cutting force versus equivalent chip thickness and for specific cutting energy versus equivalent chip thickness or material removal rate are presented. Then, they have been tested for different process conditions.

\section{Stone Machining by a Diamond Disk: Cutting Force and Specific Cutting Energy}

The cutting force may be measured by a dynamometer placed under the workpiece during the stone machining, as shown in Figure 1. A dynamometer may measure the components of the cutting force, which acts on the workpiece, along the feed rate direction and along the perpendicular to the feed rate direction, $F_{f}$ and $F_{f n}$, respectively; see Figure $2(\mathrm{a})$. The resultant $R$ of the $F_{f}$ and $F_{f n}$ components may be calculated as

$$
R=\sqrt{F_{f}^{2}+F_{f n}^{2}}
$$

The resultant $R$ forms an angle $\beta$ with the component $F_{f}$

$$
\beta=\tan ^{-1}\left(\frac{F_{f n}}{F_{f}}\right)
$$

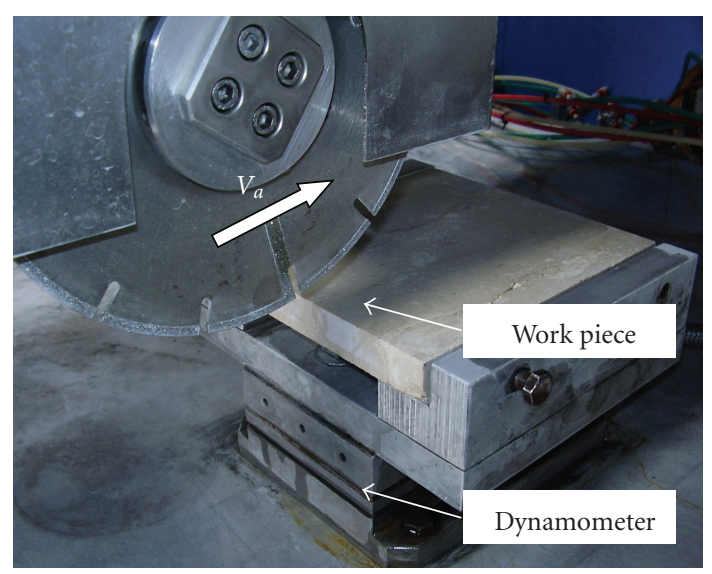

FIgURE 1: Stone machining test.

The angle of contact between disk and workpiece is given by

$$
\theta=\cos ^{-1}\left(1-\frac{2 d_{p}}{d}\right)
$$

where $d$ and $d_{p}$ are disk diameter and depth of cut

The tangential $F_{c}$ and radial $F_{t}$ components of the cutting force may be calculated by the resultant $R$ (see Figure 2(b))

$$
\begin{aligned}
& F_{c}=R \sin \delta, \\
& F_{t}=R \cos \delta,
\end{aligned}
$$

where

$$
\delta=\beta-Z \cdot \vartheta
$$

The $Z$ parameter in (5) depends on the location of the application point of the resultant force $R$ on the arc of contact $A C$ between disk and workpiece. Thus,

$$
Z=\frac{A B}{A C} .
$$

Before obtaining the components $F_{t}$ and $F_{c}$ by the measurements of $F_{f}$ and $F_{f n}$ values, some way of estimating the value of $Z$ must be found. If the depth of cut has a small value, the tangential $F_{c}$ and the $F_{f n}$ components of the cutting force roughly coincide (see Figure 2(b)). This is true when the ratio between the depth of cut and the tool diameter is smaller than $0.025 \mathrm{~mm}$. A more careful estimate of $Z$ parameter may be found by empirical investigations, such as those found in [14]. A value of 0.5 may be adopted in this work, for a depth of cut up to $0.5 \mathrm{~mm}$.

2.1. Cutting Force and Equivalent Chip Thickness. The tangential $F_{c}$ and radial $F_{t}$ cutting forces are proportional to the equivalent chip thickness $h_{\text {eq }}$ by means of a power function

$$
\begin{aligned}
& F_{t}=K_{t} \cdot h_{\text {eq }}^{v_{t}}, \\
& F_{c}=K_{c} \cdot h_{\text {eq }}^{v_{c}},
\end{aligned}
$$




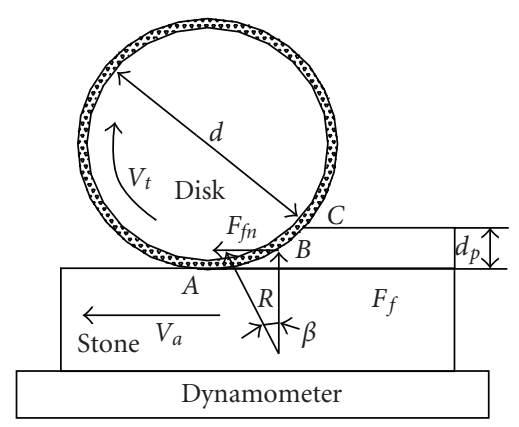

(a)

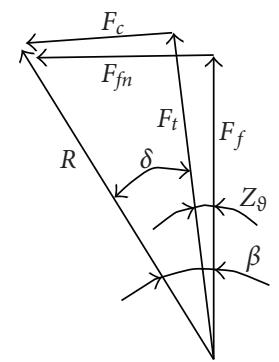

(b)

Figure 2: (a) $F_{f}$ and $F_{f n}$ measurements by dynamometer; (b) $F_{t}$ and $F_{c}$ force components.

where $K_{t}$ and $K_{c}$ are the cutting force coefficients, $v_{t}$ and $v_{c}$ are constants.

The equivalent chip thickness is equal to

$$
h_{\mathrm{eq}}=\frac{d_{p} \cdot v_{a}}{v_{t}} .
$$

It is determined by depth of cut $d_{p}$, the feed and the cutting speed, $v_{a}$ and $v_{t}$, respectively.

Since the cutting power is the product of the tangential force and the cutting speed, a nonlinear relationship also exists for cutting power. The specific cutting power can be expressed as

$$
E_{c}=\frac{F_{c} \cdot v_{t}}{v_{a} \cdot d_{p} \cdot b},
$$

where $v_{t}$ and $b$ are the cutting speed and width of cut.

The numerator is the time rate of power consumption, while the denominator is the time rate of stone volume removal. It tends to be constant for a given work material, mill specification, and undeformed chip thickness just as the fracture stress tends to have a characteristic value for a given material and type of loading. It varies significantly with chip thickness as well as with the condition of the disk face due to dressing technique and grit wear. Specific energy is a convenient quantity to use in estimating cutting forces. Substituting (8) and (9) in (10), the following result is obtained:

$$
E_{c}=\frac{K_{c}}{b} \cdot h_{\mathrm{eq}}^{v_{c}-1}=K_{e} \cdot h_{\mathrm{eq}}^{v_{e}}
$$

where $K_{e}=K_{c} / b$ and $v_{e}=v_{c}-1$.

The material removal rate (MRR) takes into account the most important process parameters, and it is given by

$$
\operatorname{MRR}=v_{a} \cdot d_{p} \cdot b .
$$

Substituting (9) in (12),

$$
\mathrm{MRR}=h_{\mathrm{eq}} \cdot v_{t} \cdot b,
$$

and therefore

$$
h_{\mathrm{eq}}=\frac{\mathrm{MRR}}{v_{t} \cdot b} .
$$

Substituting (14) in (11) results in

$$
E_{c}=\frac{K_{c}}{b^{v_{c}} \cdot v_{t}^{v_{c}-1}} \cdot \mathrm{MRR}^{v_{c}-1}=K_{m} \cdot \mathrm{MRR}^{v_{e}},
$$

where $K_{m}=K_{c} / b^{v_{c}} \cdot v_{t}^{v_{c}-1}$.

It can concluded that by defining 4 parameters $\left(K_{c}, K_{t}, v_{c}, v_{t}\right)$ it is possible to model both the cutting force $\left(F_{c}, F_{t}\right)$ and the specific cutting energy $\left(E_{c}\right)$ by means of (7), (8), (10), and (15). Those equations are general, they are valid for different values of cutting parameters, as we demonstrate in the following section.

2.2. Cutting Force and Maximum Chip Thickness. Cutting forces play an important role in all stone machining processes. They are a function of the maximum chip thickness and the geometry of the idealised sawing chip; see Malkin and Hwang [10], Milton [14]. Different chip shapes lead to different sawing behaviour. The shape of the idealised chip is often characterised by the maximum thickness $\left(h_{c}\right)$ and the length of the chip $\left(l_{c}\right)$.

The maximum chip thickness is equal to

$$
h_{c}=\sqrt{\frac{6 \cdot d_{p} \cdot V_{a}}{C \cdot r \cdot v_{t} \cdot l_{c}}},
$$

where $C$ is the density of the active grain distribution on the tool surface, $l_{c}$ is the chip length, $r=b_{c} / h_{c}$ is the chip shape ratio, and $b_{c}$ is the average width of the chips.

The density of the active grain distribution on the mill surface, $C$, and the with chip shape ratio, $r$, have been calculated in previous study by Carrino et al. [15].

The cutting force is proportional to the maximum chip thickness $h_{c}$ by means of a power function

$$
\begin{aligned}
& F_{c}=H_{c} \cdot h_{c}^{\varepsilon_{c}}, \\
& F_{t}=H_{t} \cdot h_{c}^{\varepsilon t},
\end{aligned}
$$

where $F_{c}$ and $F_{t}$ are the tangential and radial force, $H_{c}$ and $H_{t}$ are the cutting force coefficients, while $\varepsilon_{c}$ and $\varepsilon_{t}$ are constants.

\section{Experimental Test}

Experiments were undertaken on a Brembana CNC machining centre. An electroplated diamond disk is commonly used 
TABle 1: Tool properties.

\begin{tabular}{lc}
\hline Tool properties & Diamond disk \\
\hline Diamond mesh $(\#)$ & $45 / 50$ \\
Diamond concentration $\left(\right.$ grain $\left./ \mathrm{mm}^{2}\right)$ & 2.2 \\
Tool diameter $(\mathrm{mm})$ & 180 \\
Tool thickness $(\mathrm{mm})$ & 5 \\
\hline
\end{tabular}

Table 2: Mechanical properties of Coreno Perlato Royal and White Carrara marbles.

\begin{tabular}{lcc}
\hline Material properties & Coreno Perlato Royal & $\begin{array}{c}\text { White Carrara } \\
\text { Carrara }\end{array}$ \\
\hline Density $\left(\mathrm{kg} / \mathrm{m}^{3}\right)$ & 2740 & 2705 \\
Water absorption $(\%)$ & 4.0 & 0.06 \\
Compressive strength $(\mathrm{MPa})$ & 163 & 131 \\
Young modulus $(\mathrm{MPa})$ & 72000 & 75000 \\
Flexural strength $(\mathrm{MPa})$ & 12.8 & 16.9 \\
Abrasion resistence & 0.95 & 0.52 \\
Impact resistance $(\mathrm{cm})$ & 32 & 61 \\
Knoop hardness $(\mathrm{MPa})$ & 2001 & 1463 \\
\hline
\end{tabular}

TABle 3: Experimental plan.

\begin{tabular}{lcc}
\hline Factors & no. Levels & Levels \\
\hline Cutting depth (mm) & 14 & $0.01-0.02-0.03-0.04-0.05-0.06-$ \\
& & $0.07-0.08-0.09-0.1-0.2-0.3-0.4-0.5$ \\
Feed speed (mm/min) & 3 & $200-400-600$ \\
Cutting speed (rpm) & 1 & 2000 \\
Replications & 3 & \\
\hline Total cuts & 126 & \\
\hline
\end{tabular}

to cut ornamental stone. Its tool properties are shown in Table 1.

The workpiece material was Coreno Perlato Royal marble. It mainly consists of $\mathrm{CaCO}_{3}$ with inclusions of seaweed and fossils that produce light and dark spots appreciated from an aesthetic point of view. Its mechanical properties are shown in Table 2 in comparison with those of well-known White Carrara marble.

Three feed speed values and fourteen cutting depth values were taken into account; they were chosen in order to reproduce the commonly used industrial range of process variables. Each cut was replicated three times, yielding a total of 126 measured forces. The experimental plan is shown in Table 3. The cutting conditions were represented by the equivalent chip thickness $h_{\text {eq. The }}$ experimental cuts were performed in a random sequence, in order to reduce the effect of any possible systematic error. The cutting forces $F_{f n}$ and $F_{f}$ have been measured by a Kistler piezoelectric platform dynamometer (Type $9257 \mathrm{BA}$ ).

\section{Result Discussion}

ANOVA analysis underlined that both feed rate and depth of cut significantly influence the force components $F_{f n}$ and

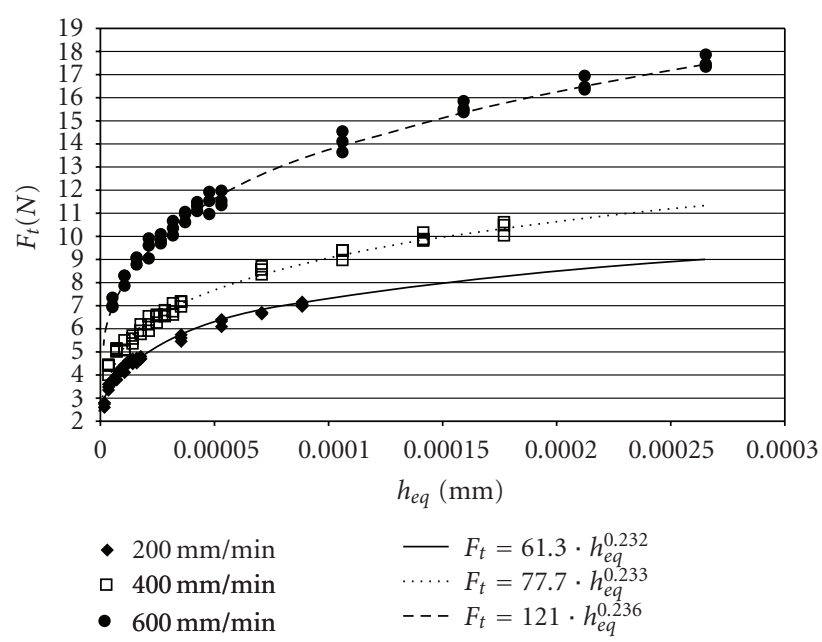

Figure 3: Comparison of model and experimental data of $F_{t}$ versus $h_{\mathrm{eq}}$ and $v_{a}$.

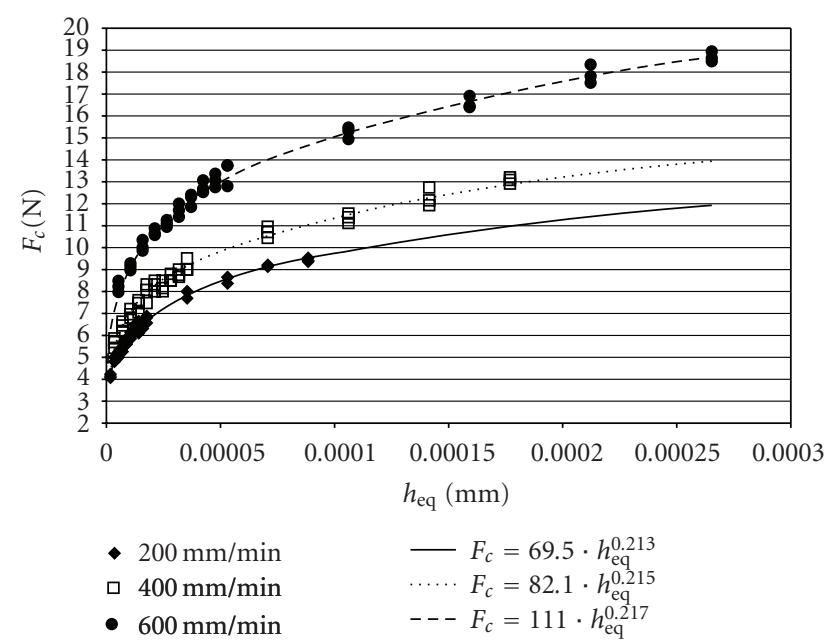

FIGURE 4: Comparison among model and experimental data of $F_{c}$ versus $h_{\mathrm{eq}}$ and $v_{a}$.

$F_{f}$, even if the depth of cut seems to be the most significant variable. An increase of both the depth of cut and the feed speed causes an increase of both force components.

Regression analysis of the experimental data was carried out to the constant values in (7), (8), (11), (15), (17). The coefficients of determination were higher than $98 \%$, while the hypotheses (normality and homogeneity of variance) about the residuals were satisfied. The radial cutting force $F_{t}$ versus the increase of the equivalent chip thickness and the feed speed is reported in Figure 3. It increases with the increase of the feed speed from a maximum of $8 \mathrm{~N}$ at $200 \mathrm{~mm} / \mathrm{min}$ to $18 \mathrm{~N}$ at $600 \mathrm{~mm} / \mathrm{min}$. The tangential cutting force $F_{c}$ versus the increase of the equivalent chip thickness and the feed speed is shown in Figure 4. It increases with the increase of the equivalent chip thickness from a maximum of $12 \mathrm{~N}$ at $200 \mathrm{~mm} / \mathrm{min}$ to $18 \mathrm{~N}$ at $600 \mathrm{~mm} / \mathrm{min}$. The values of the tangential cutting force $F_{c}$ are comparable with those of the radial cutting force $F_{t}$. 


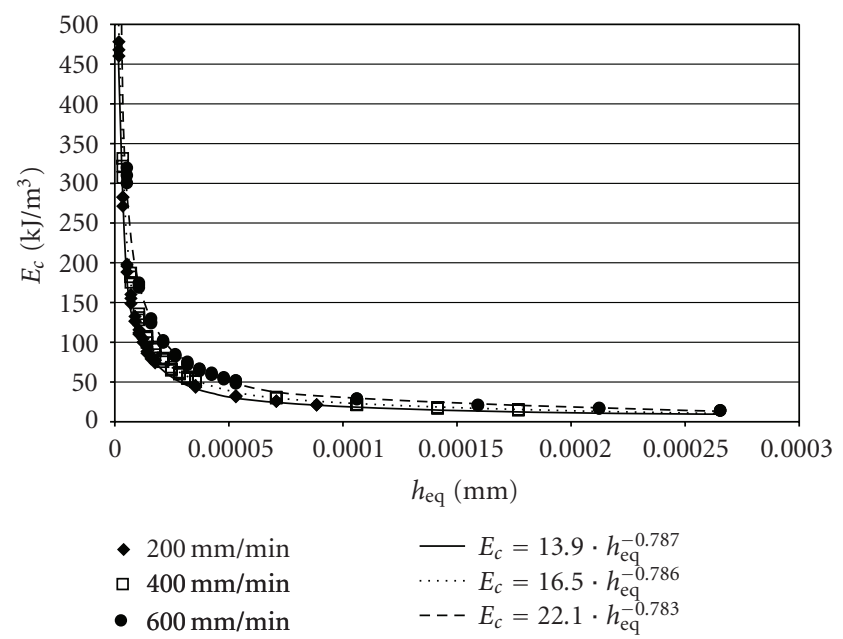

FIGURE 5: Comparison among model and experimental data of $E_{c}$ versus $h_{\mathrm{eq}}$ and $v_{a}$.

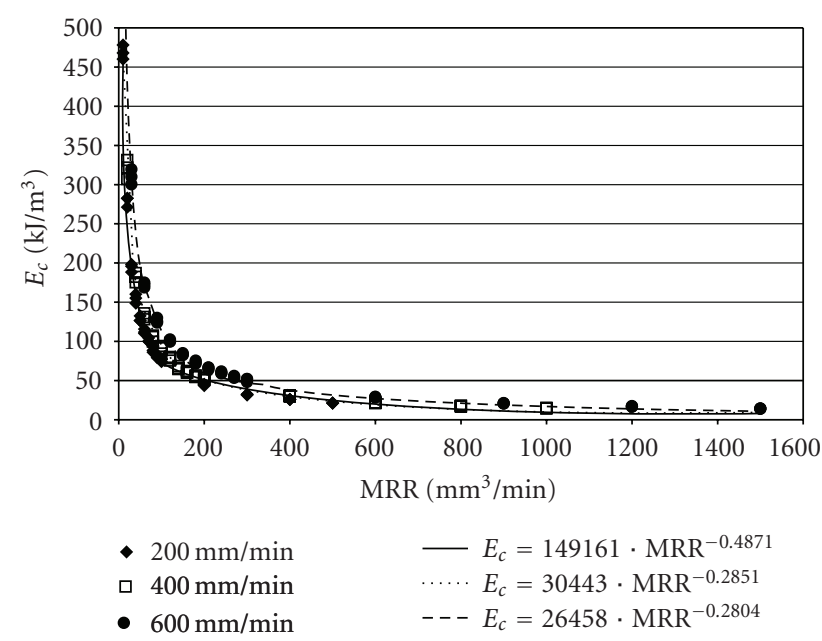

Figure 6: Comparison among model and experimental data of $E_{c}$ versus MRR and $v_{a}$.

The specific cutting energy $E_{c}$ versus the increase of the equivalent chip thickness $h_{\mathrm{eq}}$ and the feed speed is shown in Figure 5. It decreases with the increase of the equivalent chip thickness from a maximum of $480 \mathrm{~kJ} / \mathrm{m}^{3}$ at $200 \mathrm{~mm} / \mathrm{min}$ to $320 \mathrm{~kJ} / \mathrm{m}^{3}$ at $600 \mathrm{~mm} / \mathrm{min}$. Finally, the relationship between the specific cutting energy $E_{c}$ and the MRR appears to be well explained by (15). An increase of MRR involves a decrease of $E_{c}$ specific cutting energy, as shown in Figure 6 for the three considered values of the feed speed.

The radial cutting force $F_{t}$ versus the increase of the maximum chip thickness is reported in Figure 7. The tangential cutting force $F_{c}$ versus the increase of the maximum chip thickness is shown in Figure 8.

\section{Conclusion}

This work shows the models to foresee the cutting force and energy as a function of the process parameters in

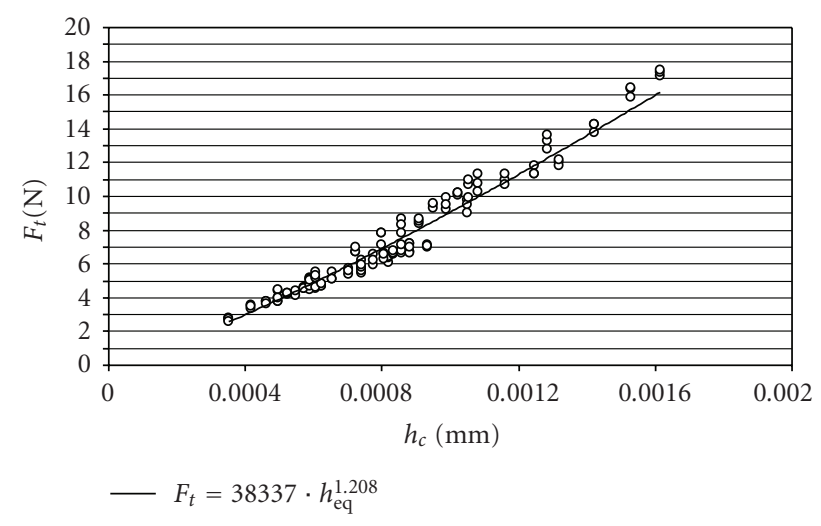

Figure 7: Comparison of model and experimental data of $F_{t}$.

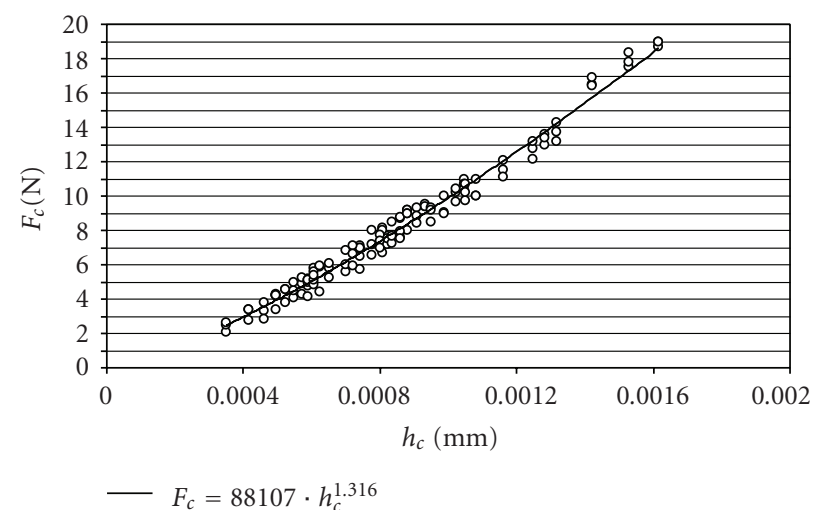

Figure 8: Comparison of model and experimental data of $F_{c}$.

the widespread stone machining by electroplated diamond disk. ANOVA demonstrated that the cutting force strongly depends on both the depth of cut and the feed speed. The influence of those two parameters has been synthetically considered by means of the equivalent chip thickness or the material removal rate (MRR). The relationship between cutting force (or specific cutting energy) and equivalent chip thickness (or MRR) was modelled by power function for three different feed speeds, $200 \mathrm{~mm} / \mathrm{min}, 400 \mathrm{~mm} / \mathrm{min}$, and $600 \mathrm{~mm} / \mathrm{min}$.

Also, the cutting force components depend on the maximum thickness of chip removed by single diamond.

The obtained models are effective, simple, and general. They represent a first step towards the optimisation of the stone machining diamond disk.

\section{Nomenclature}

$b$ : Width of cut ( $\mathrm{mm})$

$d_{p}$ : Depth of cut (mm)

$h_{c}$ : Maximum chip thickness $(\mathrm{mm})$

$v_{t}$ : Cutting speed $(\mathrm{m} / \mathrm{min})$

$f$ : Feed rate (mm/root)

$C$ : Density of active diamond grits

$r$ : Shape of chip section

$l_{c}$ : Chip length $(\mathrm{mm})$ 


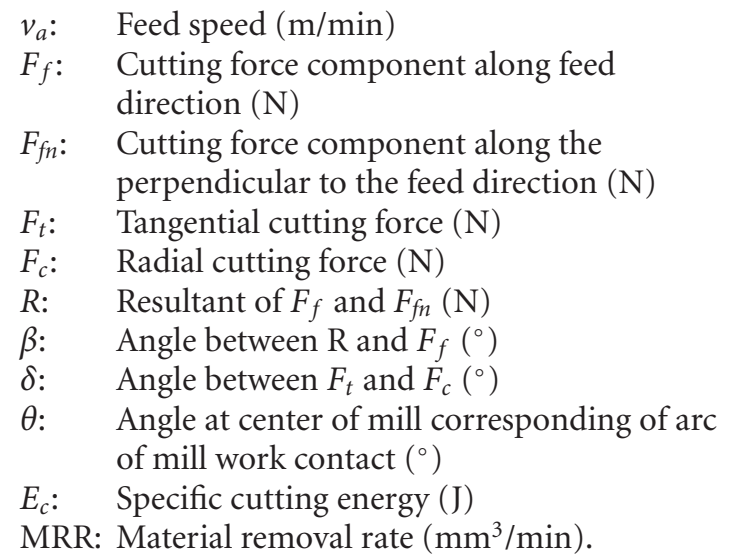

\section{Acknowledgment}

This work has been carried out with the support of the Italian MIUR (Ministry of Instruction, University and Research).

\section{References}

[1] H. D. Jerro, S. S. Pang, C. Yang, and R. A. Mirshams, "Kinematics analysis of the chipping process using the circular diamond saw blade," Journal of Manufacturing Science and Engineering, Transactions of the ASME, vol. 121, no. 2, pp. 257264, 1999.

[2] K. Brach, D. M. Pai, E. Ratterman, and M. C. Shaw, "Grinding forces and energy," Journal of Engineering for Industry, vol. 110, no. 1, pp. 25-31, 1988.

[3] J. Asche, H. K. Tönshoff, and T. Friemuth, "Cutting Principles, wear and applications of diamond tools in the stone and civil engineering industry," in Proceedings of Diamond Tools Conference, pp. 151-157, 1999.

[4] H. K. Tönshoff and G. Warnecke, "Research on stone sawing," in Advances in Ultrahard Materials Applications Technology, P. Daniel, Ed., vol. 1, pp. 36-49, Hornbeam, London, UK, 1982.

[5] J. Konstanty, "Theoretical analysis of stone sawing with diamonds," Journal of Materials Processing Technology, vol. 123, no. 1, pp. 146-154, 2002.

[6] D. M. Pai, E. Ratterman, and M. C. Shaw, "Grinding swarf," Wear, vol. 131, no. 2, pp. 329-339, 1989.

[7] C. Y. Wang and R. Clausen, "Marble cutting with single point cutting tool and diamond segments," International Journal of Machine Tools and Manufacture, vol. 42, no. 9, pp. 1045-1054, 2002.

[8] A. Di Ilio and A. Togna, "A theoretical wear model for diamond tools in stone cutting," International Journal of Machine Tools and Manufacture, vol. 43, no. 11, pp. 1171$1177,2003$.

[9] A. Ersoy, S. Buyuksagic, and U. Atici, "Wear characteristics of circular diamond saws in the cutting of different hard abrasive rocks," Wear, vol. 258, no. 9, pp. 1422-1436, 2005.

[10] T. W. Hwang and S. Malkin, "Grinding mechanisms and energy balance for ceramics," Journal of Manufacturing Science and Engineering, Transactions of the ASME, vol. 121, no. 4, pp. 623-631, 1999.

[11] T. W. Hwang and S. Malkin, "Upper bound analysis for specific energy in grinding of ceramics," Wear, vol. 231, no. 2, pp. 161-171, 1999.
[12] H. K. Tönshoff, J. Peters, I. Inasaki, and T. Paul, "Modelling and simulation of grinding processes," Annals of the CIRP, vol. 41, no. 2, pp. 677-688, 1992.

[13] X. Chen, W. B. Rowe, D. R. Allanson, and B. Mills, "A grinding power model for selection of dressing and grinding conditions," Journal of Manufacturing Science and Engineering, Transactions of the ASME, vol. 121, no. 4, pp. 632-637, 1999.

[14] M. C. Shaw, Principles of Abrasive Processing, Oxford Science, Oxford, UK, 1996.

[15] L. Carrino, W. Polini, and S. Turchetta, "Stone chipping volume using a diamont mill," in Proceedings of the 16th International Conference on Production Research (ICPR '01), p. 113, Prague, Czech Republic, July-August 2001, Summaries no. 5 . 

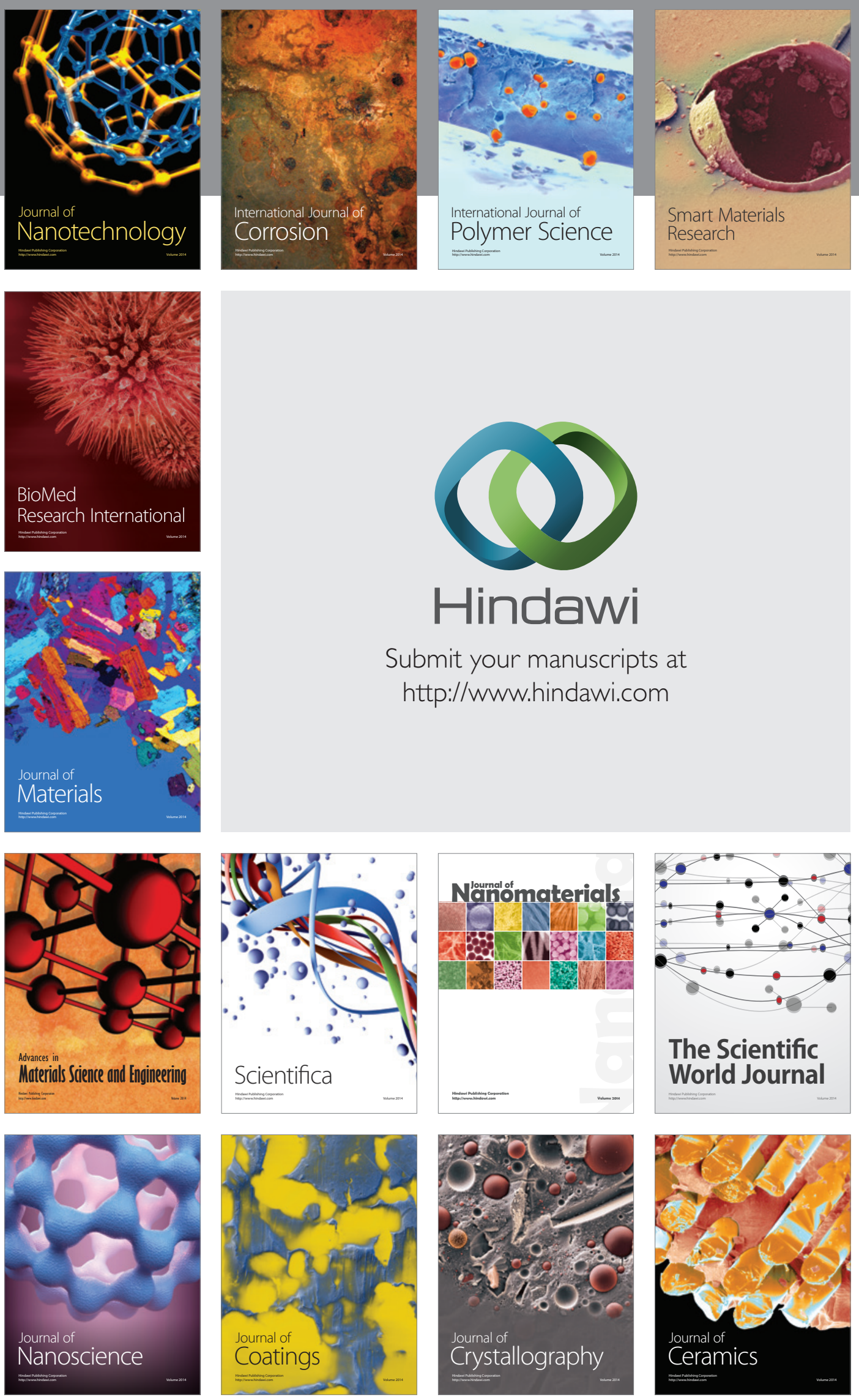

The Scientific World Journal

Submit your manuscripts at

http://www.hindawi.com

\section{World Journal}

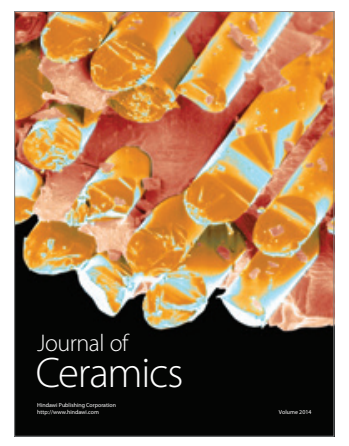

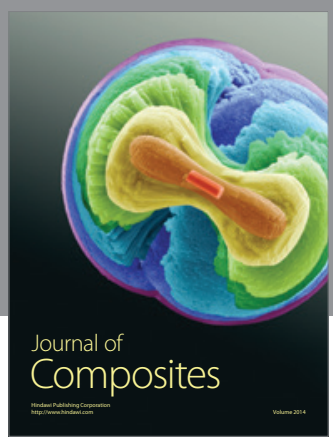
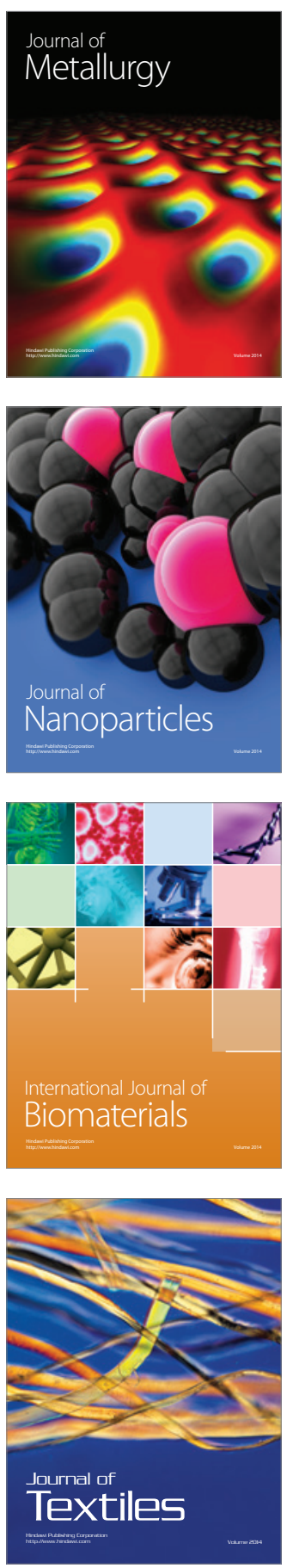